\title{
Headache and musculoskeletal complaints among subjects with self reported whiplash injury. The HUNT-2 study
}

Rigmor Myran ${ }^{1 *}$, Knut Hagen $^{1 \dagger}$, Sven Svebak ${ }^{1 \dagger}$, Oystein Nygaard ${ }^{1,2+}$ and John-Anker Zwart ${ }^{1,2,3+}$

\begin{abstract}
Background: To evaluate the life-time prevalence of self reported whiplash injury and the relationship to chronic musculoskeletal complaints (MSCs) and headache in a large unselected adult population.

Methods: Between 1995 and 1997, all inhabitants 20 years and older in Nord-Trondelag county in Norway were invited to a comprehensive health survey. Out of 92,936 eligible for participation, a total of 59,104 individuals (63.6\%) answered the question about whiplash injury (whiplash). Among these, 46,895 (79.3\%) responded to the questions of musculoskeletal complaints and headache.

Results: The total life-time prevalence of self reported whiplash injury was 2.9\%, for women $2.7 \%$ and for men 3.0\%. There was a significant association between self reported whiplash injury and headache $(\mathrm{OR}=2.1 ; 95 \% \mathrm{Cl}$ 1.8-2.4), and chronic MSCs (OR = 3.3; 95\% Cl 2.8-3.8), evident for all ten anatomical sites investigated. The association was most pronounced for those with a combination of headache and chronic MSC for both men (OR $=4.8 ; 95 \% \mathrm{Cl} 3.6-6.2)$ and women $(\mathrm{OR}=5.2 ; 95 \% \mathrm{Cl} 3.7-7.1)$.
\end{abstract}

Conclusions: Subjects with self reported whiplash injury had significantly more headache and musculoskeletal complaints than those without, and may in part be due to selective reporting. The causal mechanism remains unclear and cannot be addressed in the present study design.

\section{Background}

Whiplash injury occurs due to an acceleration-deceleration energy transfer to the neck resulting from motorvehicle collisions, and the term whiplash associated disorders (WAD) was introduced in order to describe the sign and symptoms associated with the injury [1].

The prognosis of whiplash injuries show highly variable results and may be due to differences in study populations and definitions of outcome [2]. Usually the prognosis of whiplash is favorable and self-limited. The natural course for those that report symptoms after a whiplash trauma will in most cases be rapid improvement of pain and disability the first three months $[3,4]$. Beyond three months there is usually little improvement. It is not clear which patients are at risk of delayed

\footnotetext{
* Correspondence: rigmor.myran@ntnu.no

† Contributed equally

${ }^{1}$ Faculty of Medicine, Norwegian University of Science and Technology

(NTNU), 7030 Trondheim, Norway

Full list of author information is available at the end of the article
}

recovery following whiplash injury $[5,6]$, but a slow or poor recovery of neck pain seems to be associated with psychological factors, compensation or legal factors and initial self reported symptom severity [7]. The course of recovery in WAD is very similar to the course of neck pain in the general population [8]. Headache, neck pain and other subjective complaints are common in the general population [9-12], and both headache and neck pain are equally frequent in patients with and without a history of whiplash [13]. Headache is commonly reported after a whiplash trauma [14], but the validity of the acute and chronic whiplash headache included in the ICHD-2 criteria [15] are questionable and represents most likely occurrences of pre-accidental primary headaches like migraine and tension-type headache $[16,17]$, The prognosis of headache after a whiplash trauma is good and similar to non-traumatized controls [18].

The construct validity of the whiplash syndrome is questionable [19], and several studies report an association between whiplash injury and a wide variety of
C Biomed Central

(c) 2011 Myran et al; licensee BioMed Central Ltd. This is an Open Access article distributed under the terms of the Creative Commons Attribution License (http://creativecommons.org/licenses/by/2.0), which permits unrestricted use, distribution, and reproduction in any medium, provided the original work is properly cited. 
symptoms and pain in other areas not restricted to the head and neck region [20-25]. Two studies have specifically evaluated the risk factors associated with the occurrence of wide spread bodily pain after motor vehicle collision [22,24], but these studies included insurance claimants and it is therefore not known whether there is an increased prevalence of musculoskeletal complaints (MSCs) among subject with self reported whiplash injury in the general population. Thus the main purpose of the present study was to study the relationship between self reported whiplash injury and chronic MSCs and headache in a large unselected adult population.

\section{Methods}

\section{Study population}

In the years 1995 to 1997, all inhabitants aged 20 years and above in the County of Nord-Trondelag of Norway were invited to participate in the Nord-Trondelag Health Study (HUNT-2). Out of 92,936 invited individuals, 66,140 (71.2\%) took part in the study. The target population and the description of the participants and non-participants have been published previously [26]. In short, two questionnaires including more than 200 health-related questions were administered to the participants. The first questionnaire (Q1) was enclosed with the invitation letter and delivered when attending the health examination. The second questionnaire (Q2) was filled in after the health examination and returned by mail.

\section{Questionnaires}

The Q1 included questions about MSCs adopted from the Standardized Nordic Questionnaire [27]. The Standardized Nordic Questionnaire has previously been evaluated and found to give reliable estimates for low-back pain, and upper limb and neck discomfort, in particular for symptoms during the past year [28,29]. In Q1 participants who responded "yes" to the question "Have you during the last year continuously for at least three months suffered from pain or stiffness in muscles and joints?" were defined as having chronic MSCs. These individuals were then asked to indicate locations by "yes" or "no" responses to the following areas of the body: neck, shoulders, elbows, wrist/hands, chest/abdomen, upper back, low back, hips, knees, and/or ankles/ feet.

Subjects who answered 'yes' to the question 'Have you suffered from headache during the last 12 months?' were classified as headache sufferers. Based on data from the subsequent 12 headache questions, they were classified into two groups of either migraine or nonmigrainous headache. The diagnoses were mutually exclusive. The classification of the subjects has been described in detail previously, and has been validated by interview diagnoses [30]. In short, for headache suffering the positive predictive value (PPV) was $96 \%$ and the negative predictive value (NPV) was $56 \%$; for migraine the PPV was $84 \%$ and the NPV $78 \%$; and for nonmigrainous headache, the PPV was $68 \%$ and the NPV was $76 \%$ [30].

Whiplash injuries were investigated with the following question: "Have you ever had whiplash injury (whiplash). Out of 92,936 eligible for participation, a total of 59,104 individuals $(63.6 \%)$ answered the question about whiplash injury (whiplash) in Q1. Among these, 46,895 (79.3\%) responded to the questions of MSCs and headache. The subjects were classified into four groups based on the presence of headache and chronic MSC, as shown in Table 1.

\section{Statistical analysis}

Differences between the diagnostic groups regarding demographic data (continuous and categorical) were evaluated using parametrical and non-parametric tests. $P$-values $<0.05$ were considered statistically significant. Using logistic regression, we estimated prevalence odds ratios (OR) with 95\% confidence intervals (CI) for the association between self-reported whiplash injury in relation to headache and chronic MSCs. Potential confounders such as gender, age (10 years categories), duration of education $(<10,10-12$ and $>12$ years), smoking, use of pain medication and alcohol, anxiety and depression measured by Hospital Anxiety and Depression Scale (HADS), body mass index and physical activity were adjusted for and included in the final analysis. For HADS, a cut-off value of 8 was used, as recommended in previous studies. Statistical analyses were performed using the Statistical Package for the Social Sciences (SPSS), version 15.0 (SPSS Inc., Chicago, IL, USA).

\section{Ethics}

The Hunt-2 study was conducted in accordance with the Helsinki Declaration. The study was approved by the Regional Committee for Medical Research and Ethics in Trondheim, Norway.

\section{Results}

The total life-time prevalence of self reported whiplash injury was $2.9 \%$, for women $2.7 \%$, and for men $3.0 \%$. As demonstrated in Table 1, there was a significant difference in age between the diagnostic groups (One-way ANOVA, $\mathrm{p}<0.0001)$ and for all the different categorical variables (Kruskall-Wallis test, $\mathrm{p}<0.0001$ ). This was most pronounced for educational level, smoking, analgesic use, physical activity, anxiety and depression among those with a combination of headache and chronic MSC. Adjustments for all these confounders were made 
Table 1 Demographic data

\begin{tabular}{lllll}
\hline & No MSC or HA & HA-no MSC & MSC-no HA & MSC and HA \\
\hline Total number & 17524 & 8096 & 11195 & 10080 \\
Age (mean, SD) & $48.7(17.6)$ & $40.8(13.7)$ & $56.0(15.6)$ & $47.6(14.0)$ \\
Gender, female \% & 44.3 & 63.3 & 48.6 & 67.1 \\
Years of education >12 years (\%) & 23.7 & 27.4 & 15.4 & 18.3 \\
Current smokers (\%) & 24.6 & 28.1 & 28.3 & 33.8 \\
Analgesic use (\%) & 1.4 & 5.3 & 11.7 & 22.1 \\
HADS anxiety score >8 (\%) & 4.6 & 9.6 & 9.6 & 19.9 \\
HADS depression score >8 (\%) & 3.7 & 4.8 & 8.1 & 11.5 \\
Alcohol abstainers (\%) & 11.0 & 8.2 & 13.3 & 11.7 \\
BMI >25 (\%) & 57.9 & 52.6 & 66.1 & 60.8 \\
High physical activity (\%)** & 14.6 & 11.7 & 10.3 & 9.6 \\
\hline
\end{tabular}

$\mathrm{HA}=$ Headache, $\mathrm{MSC}=$ Musculoskeletal complaints

*Analagesic use daily or almost daily

${ }^{* *} \geq 3$ hours/week with hard physical activity.

in the final multivariate analyses. There was a significant association between whiplash injury and headache (OR = 2.1; 95\% CI 1.8-2.4), and chronic MSCs (OR = 3.3; 95\% CI 2.8-3.8). The association was most pronounced for those with a combination of headache and chronic MSC as shown in Table 2.

The association between self reported whiplash injury and chronic MSC was evident for all ten anatomical sites for both men and women (Table 3). Among women the strongest association was found for pain in the chest and/or abdomen $(\mathrm{OR}=7.1,95 \%$ CI 4.9-10.4), and for both genders the association was not stronger for neck pain than upper back pain (Table 3).

Among those with chronic MSC, 39.3\% of the subjects with whiplash injury reported that these complaints had a significant impact on their work ability compared to $25.5 \%$ of those with chronic MSC but without self reported whiplash injury $(\mathrm{p}<0.0001)$. There was also a significant difference in impact on leisure activities

Table 2 Prevalence odds ratio (OR) of self reported whiplash injury in relation to diagnostic groups

\begin{tabular}{|c|c|c|c|c|c|c|}
\hline & \multicolumn{4}{|c|}{$\begin{array}{l}\text { Men } \\
\text { Neck-distortion }\end{array}$} & \multicolumn{2}{|c|}{$\begin{array}{l}\text { Women } \\
\text { Neck-distortion }\end{array}$} \\
\hline & $\begin{array}{l}\text { Total } \\
\text { no* }\end{array}$ & $\underset{* *}{\text { No }(\%)}$ & $\begin{array}{c}\text { OR }(95 \% \\
\text { Cl) }\end{array}$ & $\begin{array}{c}\text { Total } \\
\text { no }\end{array}$ & $\%$ & $\begin{array}{l}\text { OR }(95 \% \\
\text { Cl) }\end{array}$ \\
\hline MSC -/HA & 9761 & $\begin{array}{r}135 \\
(1.4)\end{array}$ & 1.0 (ref) & 7763 & $\begin{array}{c}64 \\
(0.8)\end{array}$ & 1.0 (ref) \\
\hline $\begin{array}{l}\text { MSC -/HA } \\
+\end{array}$ & 2969 & $66(2.2)$ & $\begin{array}{c}1.6(1.1- \\
2.2)\end{array}$ & 5127 & $\begin{array}{l}83 \\
(1.6)\end{array}$ & $\begin{array}{l}1.3(0.9- \\
1.9)\end{array}$ \\
\hline $\mathrm{MSC}+/ \mathrm{HA}$ & 5758 & $\begin{array}{l}202 \\
(3.5)\end{array}$ & $\begin{array}{l}2.2(1.7- \\
2.9)\end{array}$ & 5437 & $\begin{array}{l}134 \\
(2.5)\end{array}$ & $\begin{array}{c}2.8(2.0- \\
4.2)\end{array}$ \\
\hline $\begin{array}{l}\mathrm{MSC}+/ \mathrm{HA} \\
+\end{array}$ & 3315 & $\begin{array}{l}268 \\
(8.1)\end{array}$ & $\begin{array}{c}4.8(3.6- \\
6.2)\end{array}$ & 6765 & $\begin{array}{l}404 \\
(6.0)\end{array}$ & $\begin{array}{l}5.2(3.7- \\
7.1)\end{array}$ \\
\hline
\end{tabular}

$\mathrm{HA}=$ Headache, $\mathrm{MSC}=$ Musculoskeletal complaints

Analyses adjusted for all variables in Table 1.

*Total number of subjects

${ }^{*}$ Number of subjects (and percentage) with self reported neck-distortion between these two groups $(75.4 \%$ versus $61.3 \%$, p < 0.0001). The association between self reported whiplash injury and headache was found for both migraine $(\mathrm{OR}=$ 2.2; 95\% CI 1.8-2.6) and non-migrainous headache (OR = 2.1; CI 1.7-2.4) for both genders (data not shown).

In short, for headache suffering the positive predictive value (PPV) was $96 \%$ and the negative predictive value (NPV) was 56\%; for migraine the PPV was $84 \%$ and the NPV 78\%; and for non-migrainous headache, the PPV was $68 \%$ and the NPV was $76 \%$ [30].

\section{Discussion}

In this large population-based, cross-sectional study, self-reported whiplash injury was associated with increased prevalence of headache and chronic MSCs, which was evident for all anatomical sites. Individuals with a combination of headache and chronic MSC were five times more likely to report whiplash injury than those without any complaints.

The life-time prevalence of having sustained a whiplash trauma in our study was $2.9 \%$ and is much lower than the $15.9 \%$ reported in a population-based crosssectional study among the Saskatchewan population [20]. Published reports from the Confederation of Norwegian Enterprise comprising all the Norwegian government insurance companies indicate that the most common cause of whiplash, a rear end collision, in year 2000 involved 54000 vehicles and half of these were hit from behind, i.e. 27000 people. Over a 10 year period one can calculate that approximately 270000 , i.e. $6 \%$ of the population, will be involved in such collision. In addition comes all other traffic- and sport accidents. This means that the percentage who have sustained on an accident with whiplash mechanism within a relevant time period is probably much higher than the $2.9 \%$ who self report a whiplash accident [31]. It is therefore very likely that whiplash traumas were grossly underreported 
Table 3 Prevalence odds ratio (OR) of self reported whiplash injury related to location of musculoskeletal complaints

\begin{tabular}{|c|c|c|c|c|c|c|}
\hline \multirow{3}{*}{ Location of MSCs } & \multicolumn{3}{|c|}{ Men } & \multicolumn{3}{|c|}{ Women } \\
\hline & \multicolumn{3}{|c|}{ Neck-distortion } & & \multicolumn{2}{|c|}{ Neck-distortion } \\
\hline & Total no* & No $(\%)^{* *}$ & OR $(95 \% \mathrm{Cl})$ & Total no & No (\%) & OR $(95 \% \mathrm{Cl})$ \\
\hline No MSCs & 12529 & $201(1.6)$ & 1.00 (ref.) & 12743 & $147(1.1)$ & 1.0 (ref) \\
\hline Neck & 4347 & $384(8.8)$ & $5.4(4.4-6.8)$ & 7136 & $458(6.4)$ & $6.2(4.9-7.9)$ \\
\hline Shoulders & 4957 & $326(6.6)$ & $3.7(2.9-4.6)$ & 7675 & $425(5.5)$ & $5.6(4.4-7.2)$ \\
\hline Elbows & 1679 & $113(6.7)$ & $3.8(2.8-5.1)$ & 2515 & $140(5.6)$ & $5.1(3.7-7.2)$ \\
\hline Wrist/hands & 2202 & $146(6.6)$ & $3.9(3.0-5.1)$ & 4577 & $251(5.5)$ & $4.9(3.7-6.4)$ \\
\hline Chest/abdomen & 972 & $68(7.0)$ & $3.6(2.4-5.2)$ & 1543 & $107(6.9)$ & $7.1(4.9-10.4)$ \\
\hline Upper back & 1421 & $125(8.8)$ & $5.0(3.7-6.7)$ & 3361 & $235(7.0)$ & $5.9(4.4-7.8)$ \\
\hline Low back & 4476 & $255(5.7)$ & $3.1(2.4-3.9)$ & 6399 & $326(5.1)$ & $4.8(3.8-6.3)$ \\
\hline Hips & 2693 & $155(5.8)$ & $2.9(2.2-3.9)$ & 5554 & $260(4.7)$ & $4.8(3.6-6.3)$ \\
\hline Knees & 2979 & $170(5.7)$ & $3.2(2.5-4.2)$ & 4686 & $219(4.7)$ & $4.7(3.5-6.3)$ \\
\hline Ankles/feet & 2179 & $115(5.3)$ & $3.0(2.3-4.1)$ & 3881 & $209(5.4)$ & $5.3(3.9-7.1)$ \\
\hline
\end{tabular}

$\mathrm{HA}=$ Headache, MSC = Musculoskeletal complaints. Analyses adjusted for all variables in Table 1.

*Total number of subjects with localized MSCs complaints in the population.

**Number of subjects (and percentage) with self reported neck-distortion

in the present study, and that selective reporting, e.g. among those with complaints may be present.

The present results are in accordance with previous cross-sectional studies, reporting a wide variety of health complaints among persons with self-reported whiplash injury $[20,21]$ and a Swedish cohort study showed that persons with chronic pain after a whiplash injury had an increased risk for pain from different anatomical sites [32]. There are some that argue that these symptoms might reflect central sensitization [33] but there is also a strong association between whiplash injury and psychiatric disorders [23], which might reflect a reversed causality, that is, increased risk of future self-reported whiplash injury in individuals who already have anxiety and depression [34]. Thus, the strong relationship between whiplash injury and the combination of headache and chronic MSC in the present study may, at least in part, reflect personality traits rather than biological mechanisms [35]. It should be emphasized that in studies dealing with subjective complaints like headache, musculoskeletal pain and psychiatric symptoms, the results may be influenced by a tendency to answer in a similar way all questions regarding complaints ("reporting bias") [36]. The results from the present cross-sectional study must be evaluated with caution. It cannot be determined whether whiplash injury causes neither MSCs nor headache, or whether other risk factors or a shared susceptibility causes these associations. Secondly, since both headache, chronic MSCs and whiplash injury are based on self-report, individuals with neck pain and other pain are more likely to remember and report a previous neck trauma than those without complaints, i. e. differential information (recall bias) [37].
Even though the use of validated questionnaires reduces the risk for misclassification, the questionnairebased diagnoses are not optimal when compared to interview diagnoses. There is a possibility of non-differential misclassification of diagnosis that might weaken real associations, but we think this is a minor problem as the prevalence of headache and MSC in the current population is consistent with data from other population-based studies in the Western countries $[10,12,38]$. In addition the large and unselected population and the high participating rate, reduces the risk of selection bias. Selective participation was unlikely, since neither headache, neck-distortion nor chronic MSCs were the main objectives. The impact of non-participants has been discussed in more detail previously [26], but the large sample size decreased the risk of chance findings and the wide range of data made it possible to adjust for potential confounding variables.

\section{Conclusions}

Subjects with self reported whiplash injury had significantly more headache and musculoskeletal complaints than those without, and may in part be due to selective reporting. The causal mechanism remains unclear and cannot be addressed in the present study design.

\section{Acknowledgements}

The Nord-Trondelag Health Study (The HUNT study) is a collaboration between The HUNT Research Centre, Faculty of Medicine, The Norwegian University of Science and Technology (NTNU); Norwegian Institute of Public Health; and the Nord-Trondelag County Council.

No funds were received in support of this work. No benefits in any form have been or will be received from a commercial party related directly or indirectly to the subject of this manuscript. 


\section{Author details}

${ }^{1}$ Faculty of Medicine, Norwegian University of Science and Technology (NTNU), 7030 Trondheim, Norway. ${ }^{2}$ National Centre for Diseases of the Spine, University Hospital of Trondheim, 7030 Trondheim, Norway. ${ }^{3}$ Department of Neurology, Oslo University Hospital and University of Oslo, 0407 Oslo, Norway.

\section{Authors' contributions}

RM conceived of the study and performed the statistical analysis. RM drafted the manuscript with input from the other authors. All authors read, revised and approved the final manuscript.

\section{Competing interests}

The authors declare that they have no competing interests.

Received: 8 November 2010 Accepted: 8 June 2011

Published: 8 June 2011

\section{References}

1. Spitzer WO, Skovron ML, Salmi LR, Cassidy JD, Duranceau J, Suissa S, Zeiss E: Scientific monograph of the Quebec Task Force on Whiplash-Associated Disorders: redefining "whiplash" and its management. Spine 1995, 20:15-73S.

2. Scholten-Peeters GG, Verhagen AP, Bekkering GE, van der Windt DA Barnsley L, Oostendorp RA, Hendriks EJ: Prognostic factors of whiplashassociated disorders: a systematic review of prospective cohort studies Pain 2003, 104(1-2):303-322.

3. Hendriks EJ, Scholten-Peeters GG, van der Windt DA, Neeleman-van der Steen CW, Oostendorp RA, Verhagen AP: Prognostic factors for poor recovery in acute whiplash patients. Pain 2005, 114(3):408-416.

4. Kamper SJ, Rebbeck TJ, Maher CG, McAuley JH, Sterling M: Course and prognostic factors of whiplash: a systematic review and meta-analysis. Pain 2008, 138(3):617-629.

5. Holm LW, Carroll L, Cassidy JD, Hogg-Johnson S, Cote P, Guzman J, Peloso P, Nordin M, Hurwitz E, van der Velde G, et al: The burden and determinants of neck pain in whiplash-associated disorders after traffic collisions: results of the Bone and Joint Decade 2000-2010 Task Force on Neck Pain and Its Associated Disorders. Spine (Phila Pa 1976) 2008, 33(4 Suppl):S52-59.

6. Sterling M, Jull G, Vicenzino B, Kenardy J, Darnell R: Physical and psychological factors predict outcome following whiplash injury. Pain 2005, 114(1-2):141-148

7. Carroll L, Holm LW, Hogg-Johnson S, Cote P, Cassidy JD, Haldeman S, Nordin M, Hurwitz EL, Carragee EJ, van der Velde G, et al: Course and prognostic factors for neck pain in whiplash-associated disorders (WAD): results of the Bone and Joint Decade 2000-2010 Task Force on Neck Pain and Its Associated Disorders. Spine (Phila Pa 1976) 2008, 33(4 Suppl): S83-92.

8. Carroll LJ, Hogg-Johnson S, van der Velde G, Haldeman S, Holm LW, Carragee EJ, Hurwitz EL, Cote P, Nordin M, Peloso PM, et al: Course and prognostic factors for neck pain in the general population: results of the Bone and Joint Decade 2000-2010 Task Force on Neck Pain and Its Associated Disorders. Spine (Phila Pa 1976) 2008, 33(4 Suppl): S75-82.

9. Eriksen HR, Svendsrød R, Ursin G, Ursin H: Prevalence of subjective health complaints in the Nordic European countries in 1993. J Public Health 1998, 8(4):294-298

10. Hagen K, Einarsen C, Zwart JA, Svebak S, Bovim G: The co-occurrence of headache and musculoskeletal symptoms amongst 51050 adults in Norway. Eur J Neurol 2002, 9(5):527-533.

11. Hogg-Johnson S, van der Velde G, Carroll LJ, Holm LW, Cassidy JD, Guzman J, Cote P, Haldeman S, Ammendolia C, Carragee E, et al: The burden and determinants of neck pain in the general population: results of the Bone and Joint Decade 2000-2010 Task Force on Neck Pain and Its Associated Disorders. Spine (Phila Pa 1976) 2008, 33(4 Suppl):S39-51

12. Stovner $L$, Zwart JA, Hagen K, Terwindt GM, Pascual J: Epidemiology of headache in Europe. Eur J Neurol 2006, 13(4):333-345.

13. Schrader H, Obelieniene D, Bovim G, Surkiene D, Mickeviciene D, Miseviciene I, Sand T: Natural evolution of late whiplash syndrome outside the medicolegal context. Lancet 1996, 347(9010):1207-1211.
14. Vincent MB: Cervicogenic headache: a review comparison with migraine, tension-type headache, and whiplash. Curr Pain Headache Rep 2010, 14(3):238-243.

15. The International Classification of Headache Disorders. Cephalalgia , 2 2004, 24(Suppl 1):9-160.

16. Stovner $\sqcup$, Obelieniene D: Whiplash headache is transitory worsening of a pre-existing primary headache. Cephalalgia 2008, 28(Suppl 1):28-31.

17. Stovner $L$ : Whiplash headache: does the diagnosis make more harm than the whiplash? Cephalalgia 2010, 30(5):517-518.

18. Obermann M, Nebel K, Riegel A, Thiemann D, Yoon MS, Keidel M, Stude P, Diener $\mathrm{H}$, Katsarava Z: Incidence and predictors of chronic headache attributed to whiplash injury. Cephalalgia 2010, 30(5):528-534.

19. Stovner $\sqcup:$ The nosologic status of the whiplash syndrome: a critical review based on a methodological approach. Spine (Phila Pa 1976) 1996, 21(23):2735-2746.

20. Cote P, Cassidy JD, Carroll L: Is a lifetime history of neck injury in a traffic collision associated with prevalent neck pain, headache and depressive symptomatology? Accident; analysis and prevention 2000, 32(2):151-159.

21. Ferrari R, Russell AS, Carroll LJ, Cassidy JD: A re-examination of the whiplash associated disorders (WAD) as a systemic illness. Annals of the rheumatic diseases 2005, 64(9):1337-1342.

22. Holm LW, Carroll L, Cassidy JD, Skillgate E, Ahlbom A: Widespread pain following whiplash-associated disorders: incidence, course, and risk factors. The Journal of rheumatology 2007, 34(1):193-200.

23. Wenzel HG, Haug $T$, Mykletun A, Dahl AA: A population study of anxiety and depression among persons who report whiplash traumas. Journal of psychosomatic research 2002, 53(3):831-835.

24. Wenzel HG, Mykletun A, Nilsen TI: Symptom profile of persons selfreporting whiplash: a Norwegian population-based study (HUNT 2). Eur Spine J 2009, 18(9):1363-1370.

25. Wynne-Jones G, Jones GT, Wiles NJ, Silman AJ, Macfarlane GJ: Predicting new onset of widespread pain following a motor vehicle collision. The Journal of rheumatology 2006, 33(5):968-974.

26. Holmen J, Midthjell K, Krüger $\varnothing$, Langhammer A, Holmen TL, Bratberg GH, Vatten L, Lund-Larsen PG: The Nord-Trondelag Health Study 1995-97 (HUNT 2): Objectives, contents, methods and participation. Nor J Epidemiol 2003, 13(1):19-32.

27. Kuorinka I, Jonsson B, Kilbom A, Vinterberg H, Biering-Sorensen F, Andersson G, Jorgensen K: Standardised Nordic questionnaires for the analysis of musculoskeletal symptoms. Applied ergonomics 1987, 18(3):233-237.

28. Franzblau A, Salerno DF, Armstrong TJ, Werner RA: Test-retest reliability of an upper-extremity discomfort questionnaire in an industrial population. Scandinavian journal of work, environment \& health 1997, 23(4):299-307.

29. Palmer K, Smith G, Kellingray S, Cooper C: Repeatability and validity of an upper limb and neck discomfort questionnaire: the utility of the standardized Nordic questionnaire. Occupational medicine (Oxford, England) 1999, 49(3):171-175.

30. Hagen K, Zwart JA, Vatten L, Stovner LJ, Bovim G: Head-HUNT: validity and reliability of a headache questionnaire in a large population-based study in Norway. Cephalalgia 2000, 20(4):244-251.

31. Schrader H, Stovner LJ, Ferrari R: Chronic whiplash syndrome-an overview. Tidsskrift for den Norske laegeforening 2002, 122(13):1296-1299.

32. Berglund A, Alfredsson $L$, Jensen I, Cassidy JD, Nygren A: The association between exposure to a rear-end collision and future health complaints. Journal of clinical epidemiology 2001, 54(8):851-856.

33. Curatolo M, Arendt-Nielsen L, Petersen-Felix S: Central hypersensitivity in chronic pain: mechanisms and clinical implications. Physical medicine and rehabilitation clinics of North America 2006, 17(2):287-302.

34. Mykletun A, Glozier N, Wenzel HG, Overland S, Harvey SB, Wessely S, Hotopf M: Reverse causality in the association between whiplash and symptoms of anxiety and depression. The HUNT study. Spine (Phila Pa 1976) 2011.

35. Macleod J, Davey Smith G, Heslop P, Metcalfe C, Carroll D, Hart C: Psychological stress and cardiovascular disease: empirical demonstration of bias in a prospective observational study of Scottish men. BMJ (Clinical research ed) 2002, 324(7348):1247-1251.

36. Podsakoff PM, MacKenzie SB, Lee JY, Podsakoff NP: Common method biases in behavioral research: a critical review of the literature and recommended remedies. The Journal of applied psychology 2003, 88(5):879-903. 
37. Kristensen P: [Bias from dependent errors in observational studies]. Tidsskrift for den Norske laegeforening 2005, 125(2):173-175.

38. Bergman S, Herrstrom P, Hogstrom K, Petersson IF, Svensson B, Jacobsson LT: Chronic musculoskeletal pain, prevalence rates, and sociodemographic associations in a Swedish population study. The Journal of rheumatology 2001, 28(6):1369-1377.

\section{Pre-publication history}

The pre-publication history for this paper can be accessed here: http://www.biomedcentral.com/1471-2474/12/129/prepub

doi:10.1186/1471-2474-12-129

Cite this article as: Myran et al: Headache and musculoskeletal complaints among subjects with self reported whiplash injury. The HUNT-2 study. BMC Musculoskeletal Disorders 2011 12:129.

Submit your next manuscript to BioMed Central and take full advantage of:

- Convenient online submission

- Thorough peer review

- No space constraints or color figure charges

- Immediate publication on acceptance

- Inclusion in PubMed, CAS, Scopus and Google Scholar

- Research which is freely available for redistribution

Submit your manuscript at www.biomedcentral.com/submit 